\title{
Ssciendo
}

Ethics \& Bioethics (in Central Europe), 2019, 9(1-2), 11-16

DOI:10.2478/ebce-2019-0002

\section{"Verbindlichkeit": Some drafts of a groundwork in moral philosophy}

\author{
Werner Moskopp ${ }^{1}$
}

\begin{abstract}
All of metaethical positions today can be replaced by a universal architecture of moral philosophy, all but one: moral realism. Here, I use the term "metaethics" to refer to any theory of ethics concerning the groundwork of ethics, on the one hand, and the inquiry of the use of philosophical words, concepts or methods on the other. In this article, I will present my hypothesis that in moral philosophy, we do not need any specialized metaethics at all. Metaethics as a discipline of philosophy is only required by the work of moral realists, who try to show us a realm of values and norms that exist (per se) naturally, non-naturally or supernaturally. How can they know? The effort of metaethical realists cannot be proven either in ontology or in the philosophy of language or in cognitive science or in any meta-science that works en plus to ethics, because even in every additional discipline, we have to accept the presupposition of a validity of judgments. So, let us try it the other way around; we have to find a way to found ethics by following its structures, and that means, based on David Velleman's concepts: a) We have to search for a ubiquitous point of ethical theory in its foundation - here, no kind of value or norm can be found that is not based on a universal formal structure of normativity. b) We have to start an empirical inquiry to collect norms and values in actual use. MFT, moral psychology and moral sociology are in charge here. The combination of such an abstract groundwork with mere empirical study has to be legitimized again. Hence, I am going to try to sum up the main ideas of such a project to show the relevance of a new architecture of moral philosophy today. There is a line of reasoning that addresses the possibility of a transcendental critique in practical philosophy; therefore, it has to look into the different notions of "intuition" in moral methods like it was used by Sidgwick (Rashdall, Green, Ross, Brentano, McTaggart) and Moore on the one hand and Brentano and Bergson on the other. In my view, there is a way to combine these perspectives using the two-level-model of Hare, Singer, Greene, where "intuition" is used to categorize habits and customs of the common sense morality in general while a critical reflection uses act-utilitarian calculus to provide a universal decision - in the sense of "concrete reason" - for any possible actor in a singular situation (Hegel, Peirce, Bloch etc.). The change between these levels may be explained by means of a pragmatistic kind of continuum of research with an ideal summum bonum in the long run and a concept of common sense morality as can be found in every group or society.
\end{abstract}

Keywords: groundwork, transcendental critique, pragmatism, ubiquity, universality, personalism

To paraphrase Francis Bradley, ${ }^{2}$ I will begin this article with a consideration about the meaning of morality: If I am asked why I am to be moral, I have to start by looking at myself as a free and autonomous being. In that sense, morality must be understood as a normative and binding relation (obligation) that I am willing to follow because of the identity of this relation with a distinct relational structure of the will in all living creatures. As George E. Moore (1903) deepens this kind of thinking, we should not be confused by the polysemy of "is" in the question "What is morality?"; I do not think that we can find a thing in the natural world to point at and to say: "Look there, that is morality." The answer to that question, for all that I believe, makes a difference to the traditional argumentations in moral philosophy, and has no referential extension (has no amount in a logical sense), but it refers to a reflection that a moral being is able to perform.

What I want to emphasize is the relation of speculative and moral philosophy; that means a relationship of, say, mysticism and ethics. In that way, speculative philosophy is not an

\footnotetext{
${ }^{1}$ University of Koblenz-Landau, Campus Koblenz (Germany); email: wmoskopp@uni-koblenz.de

2 "If I am asked why I am to be moral, I can say no more than this, that what I cannot doubt is my own being now, and that, since in that being is involved a self, which is to be here and now, and yet in this here and now is not, I therefore cannot doubt that there is an end which I am to make real; and morality, if not equivalent to, is at all events included in this making real of myself" (Bradley, 1970, p. 84).
} 
argumentation without empirical correspondence but an action with some kind of contemplation of the inner sense, as if my own presence/being was included or even implicated in every thought that I think. This "fact" of consciousness might be expressed by emphasizing the mind-dependence of all human experience and knowledge. Both are hard to convey in an article such as this - but still even by reading this text and thinking all those thoughts you prove that there is something right in this concept. However, let specialists answer all those mystical assumptions.

As I remarked, the terms "obligation" or "liability" do not represent a material object and thus do not exist in the sense of something that exists as a "this" (tode ti), but designate a particular kind of relationship that belongs to consciousness. Obligation should therefore not be determined extensively by considering individual phenomena or types of liabilities, but by undertaking an intentional definition in which its proprium is emphasized as clearly as possible. The place of such a project is transcendental philosophy, at least when understood as the discipline of conceptual reflection and formal systematization. Based on my assumption, obligation can be considered as an equivalent to morality. So, this article investigates relations within practical philosophy and here within the framework of moral philosophy. I will reflect on the fact that, no matter which subject we consider regarding its normativity or valorization aspects, morality is a necessary and universally valid presupposition and therefore a formal prescription, which is also always fulfilled in every judgment - a transcendental critique should get to the essence of this fact.

Two fundamental assumptions of moral philosophy - one being synthetic sentences $a$ posteriori that are composed of material perceptions and concepts and the other one being (verbal) definitions composed of analytic sentences or the so-called "Ordinary Language Approach" - do not achieve what I will develop in the following paper. Although the following investigation remains synthetic, only pure forms of the capability of knowledge will be involved in our universal judgments. It is not possible to demonstrate/prove the transcendental critique of liability either in a mere tautology ("Normative Relation is morality.") or in an analysis of complex/metaphysical conclusions ("Morality or obligation is the combination of judgments about what is good."), but instead, liability needs to prove its own validity by carrying out its own conditions "on the fly", so to speak. Thus, the field of morality always appears in a matrix of three pure categories "consciousness-language-world".

How do I know what to look for if I am searching for the liability of liability or the obligation of obligation? Is there a kind of intuition I can rely on when it comes to the phenomena of morality? Could it be intellectual intuition or a special sensuous perception respectively feeling that can recognize a non-natural "good" as a property of a natural object? Should a deduction of duties be carried out by assuming anthropologically set properties (reason, moral sense ...), or external institutions (God, clerical dogma ...)? If one of these aspects was necessary, would that mean that it can be critically examined and legitimized/justified or would its status remain one of an arbitrary posit (like innate ideas)?

From my point of view, the only way to establish a basis for moral philosophy is to look for universal conditions of the possibility of morality, and this means, therefore, that the definition of morality has to confirm its validity in a performative way. Therefore, I propose performing an act of abstraction to highlight the unvarying aspects that are found in the manifold phenomena of our everyday moral life and to carry out a philosophical reflection on the formal structure in human moral judgments in such a way. This allows us to retrospectively conclude that the previously used various phenomena of morality have already gained validity from their underlying reasonable structure.

In accordance with Immanuel Kant and recently Robert Brandom et al. I want to define reason as the cognitive function of inference, i.e., of drawing a conclusion out of two or more premises. Therefore, a transcendental critique of practical reason is a method that depends on reason itself, for it tries to conclude a universal structure of morality for any creature with the 
capability to reason. Is such a critique impeded by its circularity? That would only be the case if reason tried to legitimate its own power. In a critique, the thinker itself concludes that there is no other way to generate judgments than to use reason - so that even the fallacy that reason has no meaning to us would show that this misconception depends on the structures of inference itself.

It is that point that G. E. Moore was dealing with when he asked his questions in Principia Ethica. Since then, metaethics has understood itself as a culmination point of theoretical reflection within moral philosophy (ontology, linguistics, epistemology, cognitive sciences). It reflects the work of normative and descriptive ethics from a second-order observation and systematizes ethical positions. However, this second order is not reflected again before categorizations take place so that the structures of metaethics themselves change from observation to observation and from object to object. In short, metaethics has not created the transcendental groundwork that I mentioned above and, therefore, it can possibly be entirely compensated by a combination of transcendental philosophy, ethics and moral psychology.

From a philosophical point of view that I share with David Velleman, morality should be examined first before we start to gather a plurality of concrete "mores" (Velleman, 2013). These belong to the fields of empirical moral research, but morality belongs to the field of transcendental philosophy. Transitions between the two levels can be examined in a continuum of research because amidst the realm of mind-dependence there is no gap, dichotomy or speculative "jump" between them. Transcendental idealism is always used as a kind of firstperson confession, that there is a universal relation between "my perspective" and the objects "I" am examining. Hence, this formal relation is ineluctable and, so to say, ubiquitous for every being with consciousness.

Furthermore, if it can be shown that pragmatism and utilitarianism could be combined with such a kind of relational idealism, then the transition from transcendental philosophy into both applied ethics and empirical moral research is fully guaranteed. In this way, the variety and flexibility of methods in empirical research can be combined with the one transcendental presupposition mentioned above. It is this ubiquity of a fundamental relationship between my view and the object examined that enables a change of roles or of putting oneself in somebody's shoes like most of the utilitarian authors suggest. While the realist's metaethical tendencies are based on a series of prescribed dichotomies (fact/value, is/ought, internalism/externalism, intrinsic/extrinsic, philosophy/common sense, primary/secondary qualities), the combination of transcendental critique and pragmatist methodology will show for moral philosophy that those dualisms are mere misunderstandings that could be avoided by clarifying the perspective used.

If we look into the depths of pragmatistic genealogy, a look that I cannot reconstruct here in detail, there we can find Kant's critical philosophy as one of its origins. Like Sami Pihlström, I advocate that a transcendental "turn" in pragmatism would have enormous advantages for the considerations of the structural moments of moral philosophy, while the pragmatist embodiment of transcendental philosophy could prepare the way for living normative ethics. Pihlström himself mentions a naturalized transcendental Critique (Pihlström, 2015, p. 79). In the basic texts of constructivist, phenomenological, utilitarian and pragmatistic thinking, fundamental, unavoidable presuppositions emerge and can be systematized in a categorical form that creates the crucial link between theoretical and practical work within moral philosophy and additionally between moral philosophy and moral sciences.

Pragmatism offers the following criteria of transcendental idealism: a) Phenomenalism: I always speak of things as appearance; things in themselves are not recognizable and can only be thought of as if they are not recognizable as such. b) Empirical Realism: Every scientific research program is itself based on the formal requirements of the validity of its judgments, experiments, explanations, etc. c) The transcendental critique discusses the condition of the possibility of knowledge formation in a theoretical and practical sense. The results of this investigation raise a claim of universal and necessary validity: While common validity (an 
agreement of principle and maxim) is generally established and corresponds to the intuitive level of Hare, the universality lies in the claim of the categorical imperative (see Kant, MdS, AA 06: p. 225.06-13), that "binds" without exception.

For normative ethics, pragmatic realism (moderate naturalism) and transcendental idealism (phenomenalism, relationality, processuality) are presumed as unavoidable research axes in whose architecture all aspects of moral philosophy (even without metaethical aspects) can be described. In favor of a continuum of inferences, it is this simultaneous restraint that excludes statements about things and values in themselves, dichotomies and bogus questions. The analysis of metaethics shows that a lot of the "non-realist" authors already attempted to constitute their metaethical positions by using (implicitly or explicitly) pragmatic arguments. Since realists are not necessarily bound to naively-objective, ontological normativity claims, but rather to facts and relational structures, transcendental idealism can be identified with empirical realism as far as the relationality of experience is confirmed by the respective author.

Thus, normativity is constituted by the binding nature of reasons and justifications, and reasons, in turn, are produced by theoretical or practical considerations. Such considerations may be compared by a deliberation (procedural/substantive) of the foreseeable material conditions and of the relationship between means and ends (Is it right for me/for us to act like this?). Looking at such a deliberation from the perspective of a second order, the degree of application varies between concrete-practical and abstract-practical dimensions. The more general norms and principles are, the more formal, in terms of the mere logical structure of thinking, are the resulting judgments. Pure universality, on the other hand, is identical with the highest degree of concretion, since it occurs in an affirmative awareness of reason. In this way, universality generates relationality and morality in the descriptive and normative facets of liability, how they appear - for each/my reason - in the concrete contexts of my "Lebenswelt".

Transcendental idealism does not exclude any position of metaethics or normative ethics or the scientific spectrum, but requires a clarification of the way in which each position is represented and, thus, it examines the effects that it has on everyday life. In this way, I see transcendental idealism as compatible with a pragmatic pluralism of methods, transcendental philosophy as compatible with life-worldly pluralism, a groundwork (Kant, GMS, AA 04) as compatible with open moral decision-making processes in everyday life. At least, transcendental realism is irrelevant for any level of scientific research.

Since I wanted to examine the conditional perspectives, according to which moral questions are to be clarified and how morality is possible, what obligatory character it has and where it becomes recognizable in actual actions, the analysis initially had different levels, too, amidst one and the same inclusion system. Every concrete moral judgment has material proportions and is therefore not universal. The foundation of morality, however, refers universally to the necessary structures of the so-called "synthetic unity of apperception" (see Kant, KrV B, AA 03: p. 126).

From a meshing of all phenomena of the simple lifeworld arise fundamental complex connections, which go beyond simplistic linear-causal processes such as the binary stimulusresponse pattern. Individuals can thus be described, integrated into their immediate environment, by an adaptive process. Every basic reflex-movement, however fundamental, is included in this concept as an active event, as it represents an individually prompted reaction, which, for other persons, can be interpreted biologically as a function of an evolutionary progression of the species and nature. In pragmatism, therefore, knowledge cannot be determined by (referentialistic) correspondence theories of distant observation, but can be used in the functional circle of a coherent truth model "on the fly" (if at all). An ultimate justification of pragmatism, or "instrumentalism", cannot be carried out in a conclusive way, since the various stages of the research process are indefinite, unfinished, and based on studies that deal with inscrutable starting points (problems). The actual dislike of pragmatists for a priori 
structures is directed against innate ideas, the prefabricated, the substantial, but not against critical thinking.

For formal moral philosophy, therefore, pragmatist methodology can only be connected to transcendental architectonics to the extent that the moment of reflection of transcendental apperception is detached from the paradigm of substance/accident. For the classical pragmatists treated here, the proximity to critical philosophy is directly provable for these aspects: universality, relationality and idealism, and synechistic "interactions". From this point of view, therefore, the scientific landscape of methods must now be linked to this methodology so that the pragmatistic movement in the architecture of moral philosophy can finally be traced back to the lifeworld.

I want to emphasize once again the advantages that I hope to gain from this step: Direct realistic positions can be detached from "exuberant" ("überschwänglich"), transcendental realism and traced back to transcendental idealism as it becomes clear that empirical research necessarily presupposes relationality. It is not without reason that Cheryl Misak, in her introductory book "The American Pragmatists" (Misak, 2013), uses the idealistically inspired work of Peirce. Also, empirical realism corresponds completely to the methodological principle of transcendental idealism. Nevertheless, this transcendental philosophy will have shot its bolt as soon as the fundamental dispute over liability can be completed. Empirically accessible phenomena of morality need to be examined more closely in terms of ordinary experience and therefore of the sciences.

However, metaethics is neither a transcendental discipline nor does it use empiricism, even less does it have any effect on the everyday questions of morality. A whole series of prejudices against transcendental idealism can be traced back to naive or speculative realism. In its transcendental forms, this kind of realism asserts that things, values, laws, norms, etc. exist in themselves and that they are either in themselves inaccessible to me or that I have special access to them (moral sense, intuition, revelation). In any case, when I explore these objects, I have exclusive contact with them as my appearances. It is the indifference of the research basis that shows how transcendental realism constantly contradicts itself, whereas transcendental idealism confirms itself. For me, the basic assumption of transcendental realism is neither provable nor refutable. In transcendental idealism, it is asserted that things, values, laws, norms, etc., as they can be described, relate to me and that they can only be thought of "as such" as a negative limitation of our knowledge: Everything that can be said about these objects comes into relation to the conscious living being and is constituted through experience processes. Therefore, "reality" must be understood as clarifying the point in which something is said to exist in real terms. So, there may be real dreams, real fictions, real ideas, etc., but also an empirical reality that forms both the basis of my everyday experiences and the basis of scientific research.

Finally, in order to radicalize my groundwork in moral philosophy, let me try to explain my position like this: I think that "I" am the only moral person in the world. That means that I am radically free but coincidentally, while reflecting on "me", I find an autonomous and indefinable/ineffable self. Therefore, to put this radical thought in relation: You are no person to me as you occur in my world of relations between phenomena. But you are a person to me as you are "I", too, in a quite formal/structural way of thinking (Vendler, 1984, p. 117). That you are thinking and willing and so on and how you think and will and so on are identical to my structural way of formal thinking - here lies the universal (ubiquitous) grounds for morality. With the system model of obligation/liability proposed here, all views and forms of involvement can be mapped in their specific aspects and typical justification strategies. In doing so, the moral experience and decision-making in a given situation can be measured with appropriate degrees of participation of the persons involved. Ethical strategies and common "moral" rules are available to the individual depending on the background of beliefs, values, and preferences. In addition, case studies and reviews serve as evidence for impact assessments. 
It can also be comprehensively worked out which conditions prevail from a scientific point of view. For example, statistics and similar situations can be used or new projects can be created. Argumentative justification strategies are then available for dealing with other participants, which may even coincide with cataloged ethical topoi (charity, duty, constraints, impact assessment, egoism, etc.). However, it must not be neglected that in addition to the existing horizon of experience of an individual kind and against the background of experiences from the traditions of human history, there is a real moral problem only if the individual gets into a moral crisis or moral conflict with other people or norms. This is where the process of ethical discourse begins as a means of reflection and evaluation of the moral criteria within the context of the lifeworld problem. In subsequent analyses of such situations, I do not want to deny anyone the possibility of continuing to work in the field of metaethical investigations. However, in the course of my studies, the suspicion has been substantiated that the acceptance of an independent discipline of metaethics itself becomes a question of ethics, namely the question of honesty and authenticity. ${ }^{3}$

\section{References}

BRADLEY, F. H. (1970): Ethical studies. London: Oxford University Press.

KANT, I. (1900 ff.). Gesammelte Schriften: Akademieausgabe (AA) [KrV B= Kritik der reinen Vernunft, zweite Auflage, AA vol. 03; GMS = Grundlegung zur Metaphysik der Sitten, AA vol. 04; MdS = Die Metaphysik der Sitten, AA vol. 06]. Berlin: de Gruyter

MISAK, Ch. J. (2013): The American pragmatists. Oxford: Oxford University Press.

MOORE, G. E. (1903/1980): Principia Ethica. London: Cambridge University Press.

PIHLSTRÖM, S. (2013): Toward pragmatically naturalized transcendental philosophy of scientific inquiry and pragmatic scientific realism. In: Studia Philosophica Estonica, 5(2), pp. 79-94.

VELLEMAN, J. D. (2013): Foundations for moral relativism. Cambridge: Open Book Publishers.

VENDLER, Z. (1984): The matter of mind. Oxford: Clarendon Press.

\footnotetext{
${ }^{3}$ To finish this article with a kind of a short conclusion or, say, to put this whole concept under one main category, I take up the proposal that a reviewer of this article made: He/she mentioned that my thoughts seem to be a kind of personalism. I would like to add that (or ask if), maybe, it is a personalism minus its Christian presuppositions, minus its aversion against materialism, which I endorse in the sense of Bloch's "Prinzip Hoffnung", minus its metaphysical connotation in asserting the reality of something beyond my own possible experience, minus its devaluation of animal consciousness, minus...(?). Maybe, if one accepts "my" own uniqueness and gives up this uniqueness for the sake of a universal feature - the ubiquity of personality -then my article is correctly categorized as a personalism in certain parts. I have to admit that because of this reviewer's remarks, I thought for one short moment that I had finally found my safe place in philosophy - and even given the fact that this restless search goes on, let me end this article by calling it a part of a transcendental or even a pragmatistic personalism.
} 